\title{
Sobre Suturas: imágenes, escritura, vida, de Daniel Link. Buenos Aires: Eterna Cadencia, 2015.
}

\author{
2. Leonel Cherri / Universidad Nacional del Litoral - Universidad de Buenos Aires - COniceT \\ clcherri@hotmail.com
}

\section{Los modos de leer y sus ventosas}

Suturas: imágenes, escritura, vida (2015) es el último libro de Daniel Link, y con él Clases: literatura y disidencia (2005) y Fantasmas: imaginación y sociedad (2009) vienen a formar una trilogía. Ese diagrama, complejo y sofisticado, retardado y elegante, surge de un choque de fuerzas que gracias a su pensamiento hoy se nos presentan como evidentes: los dispositivos de clasificación y las potencias de lo imaginario.

Cuando «Literaturas posautónomas» (diciembre de 2006) apareció en Linkillo (cosas mías), el blog de Daniel Link, hacía poco más de un año que Clases: literatura y disidencia (julio de 2005) había sido publicado por Norma. Y hacía varios años más que Link venía dictando esas clases, es decir, apostando a la literatura y a la disidencia. Quiero decir: llama poderosamente la atención que la visión «sociográfica» de Ludmer haya despertado tanta desconfianza, mientras que el libro de Link cuyas hipótesis él mismo define como historiográficas y antropológicas no constituyó ningún escándalo. Seamos precisos: ninguna polémica. ${ }^{1}$

Me refiero a un libro que sostiene que «el arte nada dice o traza salvo el umbral de una mutación antropológica» (IIO) y que «la literatura es una experiencia que, nos enseñaron, puede aparecer en cualquier parte» (50). Esta afirmación, no es menor señalarlo, se repite diez años después sobre el final de Suturas (2015:605). Por eso, antes que realizar una reseña en estrictu sensu, prefiero proponer una versión ensayística que intente seguir el planteamiento de unos problemas que Suturas formula en nuevos términos, es decir, por la vía regia de la repetición. Y con esto, lejos de reclamar un deber ser para la polémica, en general, o de esta polémica no suscitada, en particular, creo oportuno que nos detengamos en lo sintomático de la situación y, por consiguiente, en lo que en ese señalamiento podría haber de interrogable. Pues la situación de los modos de leer es, no ya una polémica, sino una problemática que atraviesa las discusiones críticas más actuales. ${ }^{2}$

Compuestos de enunciados asertivos o máximas intempestivas, tanto Clases como todo el pensamiento de Link, no han despertado mayores suspicacias. Y 
está bien que así sea, porque lo que allí hay de ensayístico no se juega tanto en las estrategias discursivas (en Suturas leemos un capítulo dedicado a la poesía compuesto prácticamente por preguntas) sino, más bien, en la forma en que introduce y plantea sus problemas, en la forma en que compone sus razonamientos diagramáticos: el montaje, la repetición, el subrayado, las variaciones, los juegos, el desplazamiento en torno a una serie, el patchwork, etcétera.

Por ejemplo, cuando se trata del problema de Cómo se lee (2003) y los modos de aparición de la literatura, la teoría que introduce el razonamiento es de... ¡Borges! En «Notas sobre (hacia) Bernard Shaw» (I95I) dice el escritor: «si me fuera dado leer cualquier página actual —ésta, por ejemplo- como la leerán el ańo dos mil, yo sabría cómo será la literatura del año dos mil» (747). Como vemos, la hipótesis borgeana sostiene que «una literatura difiere de otra (ulterior o anterior) menos por el texto que por la manera en que es leída» (Link 2005:74).

Retomo: ¿acaso Ludmer no lee la literatura por medio de una hipótesis o interrogación semejante? ¿se podría hablar «hoy en Argentina (en América Latina) de una literatura paradojalmente diaspórica, no solamente por sus territorios y sujetos (y por su posición respecto de la literatura y la ficción), sino por sus modos de circulación y de lectura»? ¿Qué fin o deceso hay allí decretado? ¿El hecho de que «junto a los bestsellers y a las escrituras "malas", lights, de ahora, seguiría existiendo la buena vieja literatura, llena de literatura y con multiplicidad de lecturas» (Ludmer 2006); no es, antes que una amenaza o decreto de muerte, una constatación del anacronismo y de la supervivencia que atraviesan los modos de leer, es decir, la literatura? A mi juicio, la hipótesis fundamental del texto de Ludmer, lo que vale la pena discutir, es la postulación de la ambivalencia como el modo (¿dominante? ¿hegemónico? ¿epocal? ¿ético?) de lectura y de aparición de la literatura en el presente. El resto es pose, «agite», experimento, trampa, etc. ¿Eso debería exasperarnos viniendo de alguien que se define como escritora?

Sandra Contreras, que dicho sea de paso es una sagaz lectora de Link, fue una de las pocas críticas que entendió esto. Respecto de los argumentos de Ludmer y de la polémica Bolivia construcciones (2006), dice Contreras:

No tendría ningún sentido ver aqui algo asi como una contradicción; por el contrario, lo que importa aquí justamente es el modo en que la ambivalencia instala en los textos, es decir, en su lectura y en su recepción, algo del orden de la indeterminación (no indefinición, sino más específicamente indeterminación) de valores (2010:I47. Yo resalto)

Pensar la ambivalencia como una contradicción puede ser acertado, sin embargo - y aquí reside la sutileza de la crítica — tal posición carece de sentido. Leamos entre líneas: no importa si hay base real para sostener tal cosa, en realidad no importa si es verdad semejante comprobación, no se trata de si «se puede»o «se debe» seguir leyendo de un modo o de otro, sino si allí hay o no hay, si se produce o no sentido. Y lo que define el sentido, nos enseñaron, es el vacío con el que se relaciona: hay sentido (memoria, verdad, política, ética) porque hay 
un acto de imaginación. Qué implica o supone lo que sucede en esos agujeros o campos estriados y cómo (a través de qué formas, medios, máquinas, armas) se sostiene es, en definitiva, lo que importa: sólo en la negación hay compromiso con lo existente.

Como podrá percibirse, la hipótesis de Borges (que, como Link nos ha enseñado, es muy probable que la esté repitiendo) no supone una cualidad crítica sino teórica, puesto que no deduce situación histórico-social-estética alguna (la de su presente o la del nuestro) sino que estableciendo la situación (una imagen) de la literatura arriesga jugarla a todos los tiempos, es decir, apuesta a lo infinito y a lo cualquiera. La potencia de la postulación borgeana se ve con claridad en lo que ha sido de Borges no sólo en Argentina o en el mundo sino en el pensamiento de Link. Por ejemplo: en Clases, Borges («que el cielo exista aunque mi lugar sea el infierno») acaba siendo arrastrado por la ascesis de San Sebastián; en Fantasmas (294), Borges se calla (es en-callado) como las sirenas y ocupa el lugar de la negatividad («desde hace años, algunos escritores posteriores a Manuel Puig, Rodolfo Walsh, Osvaldo Lamborghini, a Copi y, también, a Cesar Aira, hemos decidido olvidarnos de Borges»); en Suturas («Máquina»), Borges es arrastrado por los razonamientos diagramáticos que lo muestran (lo hacen aparecer) junto a Marcel Duchamp y a Andy Warhol como un artista vitalista y pop.

La autonomía es una antigualla, eso ya lo sabemos, pero esa es la lógica que palpita en los discursos que parecen olvidar que el lenguaje y la literatura son dispositivos. Link no desconoce esa situación, y por eso no se ha cansado de insistir que en literatura «Todo sucede en un plano de composición (que no hay que entender en un sentido técnico sino estético)» (2005:23):

Le combat des formes en Occident a été aussi acharné, sinon plus, que celui des idées ou des valeurs. Mais les choses, au xx siècle, ont pris une allure singulière: c'est le «formel» lui même, c'est le travail réfléchi sur le système des formes qui est devenu un enjeu. Et un remarquable objet d'hostilités morales, de débats esthétiques et d'affrontements politiques. (Foucault 1982:220)

Si el siglo xx es «una larga batalla en torno a lo formal», es porque las formas tienen un sentido ético y político, en suma, sensible. Es a esa batalla que Link vuelve incansablemente: la guerra civil en curso en la que la vida y sus formas se juegan entre los dispositivos de clasificación y las potencias de lo imaginario.

Tal planteo en Clases cobra un marco antropológico e historiográfico específico:

...I9I8 y 1945 son para Sloterdijk no sólo las fechas terribles que asociamos a las guerras sino las fechas de dos inventos decisivos, la radio y la televisión, a partir de los cuales se formará, hacia mediados del siglo pasado, un nuevo dispositivo de contención radicalmente diferente del humanismo, la cultura industrial (...) Radicalmente diferente, sobre todo porque se trata, ahora, de una contención paradójica que sólo ofrece la desinhibición de las potencias del hombre (aún las más atroces). Es por eso que la crisis del humanismo equivale a un retorno 
del estado salvaje (caos). Se trata de la atrocidad imperialista (la guerra), o el embrutecimiento por los medios masivos, en todo caso lo que se revela es que ese retorno se da en situaciones de alto desarrollo de poder. En ese contexto, se hace necesario volver a pensar una nueva estructura de cultivo propio («Kultivierungsstruktur»), señala Sloterdijk, diferente de la pastoral humanista entendida como política de cría (¿Cómo y para qué reproducirse?). También habrá que pensar, consecuentemente, en nuevas formas de arte. (...) Pero al haber perdido el humanismo su capacidad para producir síntesis políticas y culturales, también cesan los poderes inquietantes de las categorías centrales en su funcionamiento (...) Así es la civilización (o la cultura, según se prefiera) en la que se hunden nuestros pies. Antes del pop, sólo se encontrarán retombées (ecos anticipatorios) de la nova vita que debemos construir en la lucha de las clases y más allá de las normalizaciones, y de la cual la literatura comenzó dando sus primeras señas. $(362-363,367)$

Si la literatura ha perdido su "potencial crítico» o, mejor, «su capacidad de producir síntesis políticas y culturales», la situación no podría ser más promisoria: allí no hay que buscar ninguna lapidación sino la posibilidad que abre la improductividad y la inoperancia. Es decir, sería más conveniente restituir a tal argumento no un horizonte liberal sino uno de izquierda: busquemos la revolución por otros medios (ascéticos tal vez), busquemos otra línea de negatividad (las formas de imaginación) y volvamos a plantear el problema de la lucha de clases (es decir, en su multiplicidad). En fin: la petitio de Rodolfo Walsh que en Fantasmas hace eco:

En un congreso que se realizó en Los Ángeles durante 2008, se pretendía definir el campo de problematización que los organizadores del coloquio habían propuesto como «the new literary and cultural configurations of post-200I Argentina».

Martín Kohan leyó un trabajo muy agudo y muy preciso (...) sobre la guerra en la literatura argentina, a partir de tres o cuatro novelas (Marechal, Fogwill, Bioy). Durante la discusión de su presentación, le pregunté qué lugar ocuparía El eternauta en su esquema y él me contestó no haberlo considerado porque trabajaba solo con textos literarios. Agregó algo que me dejó pensando los días subsiguientes (en LA, en San Francisco, en México, donde volvimos a encontrarnos): «Para mí la autonomía literaria es la única garantía para poder proponer mundos alternativos».

Entendí, en esa frase, que los abismos que separaban mi presentación y la suya no eran sino producto de un equívoco terminológico, porque para mí no es la autonomía literaria, y ni siquiera la literatura (es decir, el esteticismo), la garantía de la negación (no importa qué forma esta adopte) sino el acto mismo de imaginar (...) Porque es capaz de imaginar, la conciencia es capaz de negar el mundo y lo imaginario está siempre habitado por una nada: es la negación libre e indeterminada del mundo, de acuerdo con un punto de vista que implica un compromiso con lo existente. El arte no hace sino actualizar el acto imaginante (la experiencia), proponiéndose como un análogon material (no la representación) de ese acto o experiencia.

A mi juicio, el dilema de la autonomía literaria se disuelve si uno acepta hipótesis como esas (recordadas en un cuarto de hotel de la Zona Rosa de México, mientras por mi ventana 
entran ráfagas de «música latina») y, con él, la pesadilla de los intelectuales y los escritores como sujetos privilegiados en relación con algún tipo de verdad, que es precisamente lo más penoso en las posiciones autonomizantes.

No es, como me dijo Fermín Rodríguez en el encuentro de LA, que yo acepte la hipótesis de que no hay valor, sino que me repugna la idea del «valor universal». Hay valores, claro, y los míos no necesariamente deben coincidir con los de mi vecino (y viceversa). Pretender que el punto de vista de la literatura contiene un plus de lucidez respecto de otras prácticas culturales (basándose en su presunta y regia autonomía) me parece una posición no solo ingenua sino, incluso, peligrosa. $(346-347)$

Cuando Ludmer publica Aqui América Latina: una especulación, hacía un año que Link había publicado Fantasmas. Poco tiempo después de la publicación del libro de Ludmer, Miguel Dalmaroni publicó en Bazar Americano un texto titulado «La literatura y sus restos (teoría, crítica, filosofía). A propósito de un texto de Ludmer (y de otros tres)». Esos «otros tres» serían Las musas de Jean-Luc Nancy (200I), la compilación realizada por Alberto Giordano titulada Los límites de la literatura (2010) y Fantasmas en donde Link, dice Dalmaroni, reinventa "una teoría de "la imaginación" que tiene casi nada en común con el enfoque de Ludmer» cuyas tesis de las «literaturas posautónomas» es una "mezcla de apetito por la novedad, generalizaciones conjeturales (con poca "base real") y cronologismo».

De los sólidos argumentos de Dalmaroni poco hay para decir, salvo que si «imponer la agenda» le parecía (en ese texto) una "compulsión deprimente», al parecer, acabó - como se dice en criollo- «pisando el palito». Lo que resulta si no sintomática, al menos llamativa, es la operación de Dalmaroni: hacer participar a Link de semejante otredad citándolo apenas una vez. Habiendo tantos momentos en Fantasmas, como el citado más arriba, donde la teoría de la imaginación se postula como punto de fuga de la autonomía y de la negación dialéctica; Dalmaroni escoge, justamente, el momento en que Link decide no polemizar aunque por medio de un sutil recorrido sentar posición: Katatay (2007) como informe del presente, Sueños de exterminio (2005) de Gabriel Giorgi como uno de los libros más importantes posteriores al 200I, el fin de Punto de vista —renunciar a la reproducción - como un gesto de tenebroso heroísmo frente a lo contemporáneo. Sin embargo, el gesto de Link (su evasión, su silencio ¿sirenaico?) no es algo menor: «Sea o no esto cierto, y no me interesa aquí discutirlo» (2009:408).

En este punto habría que recuperar algunas reflexiones de Raúl Antelo. Polémica no es sólo «el arte de la guerra sino, como el mismo Diccionario de Autoridades confirma, la designación de la Teología dogmática», se trata de «la continuación del combate con otras armas», una "praxis argumentativa portátil y fulminante, más cómoda que las costumbres lentas o duraderas de la dialéctica clásica, activada siempre para defender el dogma ante la irrupción de estrategias que no se duda en proclamar irrisorias e impertinentes» (87). Optar por no responder una polémica, sugiere Antelo, a veces supone reconocer en los otros lo que Roland Barthes llamaba una ventosa: 
no sólo un sujeto que se adhiere con fe y convicción a una creencia, sino el efecto de un lenguaje cuyo enigma consiste en haber transformado un sistema de demistificación en mero aparato de captura por medio del cual «le sujet militant devient le parasite (heureux) d'un type de discours». (9I)

Es decir, no siempre «el que calla otorga» pero tampoco callar implica una mera victoria (evitemos la antítesis). Se trata, mejor, de un gesto que transforma el registro de la situación agonística mediante otra forma de negatividad. Es como si Link se comportara, al menos en este asunto, como un polemista nato sin ninguna polémica a cuestas. Sin embargo, como ese otro es imaginario (más en este caso, pues nadie polemizó directamente con Link), al ser interrogado directamente, Link no ha dilatado la respuesta. Entrevistado por Gabriela Manuli, en enero de 2007, Link explica: lo que él denomina «experimental», Ludmer "posautonomía» y Sarlo «etnografía». Y agrega que, por otro lado, habría una «literatura de mercado (que se piensa a sí misma, paradójicamente, como una literatura "autónoma”)». Ese «mercado» es un dominio generado por el bestsellerismo, por los "grandes» premios literarios y las instituciones de enseńanza. En ese sentido, volviendo a Fantasmas, el «academicismo» (tal como se entiende en pintura) sería también una tendencia de esa mercantilización del arte: «la peor de las complicidades, la autonomía del arte y sus universales: la lentitud de los movimientos, la duración, el engolamiento, el sentido opaco, la autocomplacencia, el vanguardismo repetido hasta la náusea» (348-349). Es decir, la vanguardia despojada de toda ambición y experimentación — es decir, despojada del modo de leer que llamamos Cesar Aira - se convierte en un dispositivo de normalización.

Tres años más tarde, en julio de 20Io, vuelve a ser interrogado en relación con la reciente publicación de Aqui América Latina y en La gaceta de Tucumán responde:

Coincido con Ludmer en que la crisis y reformulación de lo político afecta las relaciones con la literatura. En ese sentido, el concepto de post-autonomía remite al arte como experiencia, en oposición al arte como mercancía. De un modo o de otro, la literatura no puede pensarse separadamente de las grandes tensiones de su tiempo.

Es verdad, las diferencias con los planteos de Ludmer no son menores pero, como vemos, lejos de ubicarlos en una diametral oposición Link practica una asimilación selectiva. De hecho, Suturas abre con el étimon médico de "crisis» recuperado de Giorgio Agamben y de Peter Sloterdijk e, inmediatamente después, cita a Josefina Ludmer pues, según Link, es ella quien ha "precisado las suturas que nos constituyen» (19). Lo que cita, podrán imaginárselo, es Aqui América Latina: "La crisis y reformulación de lo político» (I55-I56).

Ese comienzo, no es menor. Pues lo que supone Suturas es que «la situación de lo viviente es, hoy por hoy, crítica» (I7). Es decir: los sistemas de equivalencias puras y la falta de vocabulario se han derrumbado, el paradigma que prevalece hoy —el Estado Universal Homogéneo- no es democrático y ni siquiera polí- 
tico, todo es del orden de lo excepcional. Así las cosas, «la interrogación de lo viviente encuentra en los archivos digitales la específica declinación de la pregunta sobre cómo leemos (o leeremos) lo que en los textos y las imágenes vive todavía, el resto-de-vida que hay en ellos» (20).

Esa hipótesis, hay que entenderla, enfoca el problema de lo viviente en torno a la materialidad del lenguaje y de las artes («materialidad textual», prefiere decir Link): o sea, plantea el problema de la literatura y la vida en un sentido integral. El hombre de Cro-Magnon se define por su "compulsión al arte» y su capacidad de «articular lenguaje». Apenas después (pues para la historia de lo viviente es apenas nada), con la aparición de la imprenta las universidades se vieron obligadas a crear un metasaber sobre los libros y las bibliotecas que transformó el currículum de las humanidades: el trívium, el quadrivium, la filología. En ese sentido, la infancia de la época de la reproductibilidad digital implica una «nueva filología», una "teoría de la lectura como experimentación» que no puede eludir «la existencia de archivos digitales». Esos «nuevos modos de leer» y, diría, esa situación de la lectura en relación con lo viviente, Link los llama posfilología y diagramatología.

Así planteados parecen sinónimos. Sin embargo, aunque por momentos se superpongan, no son la misma cosa. Mientras que la posfilología problematiza la situación de lo que vive todavía en los nombres y en las imágenes, la diagramatología es el modo en que se interrogan los puntos de suturas, no sólo una teoría o método sino una ética completa: si una singularidad histórica ha impuesto su lógica al mundo en el que vivimos desplazando el sentido de los nombres y de los cuerpos, no se trata ya de crear nada nuevo sino, justamente, de seguir el trazo de esas pérdidas, de esos desmoronamientos e interrogar el vacío que los constituye, es decir, interrogar el punto de sutura (las marcas de una herida) entre la antigua cultura letrada y lo que hoy llamamos ciberculturas, entre los dispositivos de clasificación y las potencias de lo imaginario, entre — dice Link- «mi propio cuerpo, la escritura y las imágenes del mundo» (23).

En otras palabras, las de Foucault (1984), estamos frente a una ontología crítica de nosotros mismos que, como sabemos, no es una teoría, una doctrina, ni siquiera un cuerpo permanente de saber que se acumula; sino una actitud, o mejor, un mandato ético que Link ha sabido escuchar. Por eso, desde hace ańos viene, simultáneamente, realizando un análisis histórico de los límites que nos son impuestos (Clases) como un experimento de la posibilidad de rebasarlos, es decir, de la negatividad como potencia (Fantasmas).

Luego de los enfoques arqueológicos y genealógicos sobre esos choques de fuerzas, lo-que-resta, es un enfoque que interrogue su después: su plus de vida. La vida no puede ser una herida abierta como afirmaba Georges Bataille, pues en la medida que hay vida todavía hay, claro, marcas: por eso, ¡una diagramatología! Esto se comprende cabalmente cuando vemos el cuerpo del exrugbier Gareth Thomas subrayado y atravesado por marcas y epistemes (el número áureo, un motto irlandés, la divina proporción) que hinchan y comprimen el cuerpo, el 
tiempo y el espacio. Ese cuerpo que parece tan singular comparte, paradójicamente, la misma busca ignorante que el cuerpo de cualquiera: «no sé qué soy aunque estas líneas me atraviesen».

Esa es la vuelta de Suturas, su «Replay», una apuesta al presente vía el ritornello y las marcas que como estratos o palimpsestos se superponen, a veces invisiblemente, en los cuerpos, en las imágenes y en los nombres. En ese diagrama (concepto moderno), la filología (cosa rancia, categoría de un más que pasado) no es una pregunta ni metodológica ni historiográfica sino ontológica, correlativa a la pregunta por el Tiempo y la Historia. Se trata de una filología al mismo tiempo musical, visual y táctil, una filología diferencial e infraleve, tartamuda y retardada, adecuada «a las formas de vida del día después de mañana» (47). Y como «es, pues, un enamorado el que habla y dice» (Barthes:23), este modo de leer implica una «efectación al Tiempo y a los tiempos: una lectura ni cercana, ni lejana sino “en cámara lenta" " ya que no hay "separación posible entre lo que está escrito y lo que vive» (I25). ${ }^{3}$ Y lo que vive todavía, promete Link, aparecerá en ese ralentamiento. Nada menos.

Así como Clases no puede considerarse ningún princeps ( $2^{\circ}$ pieza), y Fantasmas es a la vez un retardo y un avance $\left(\mathrm{I}^{\circ}\right.$ y $3^{\circ}$ pieza), Suturas no puede ser sino un punto cero ( $0^{\circ}$ pieza): el umbral definitivo («Tornada»), lo neutro, el vacío y la multiplicación, simultáneamente.

Por eso, Link vuelve nuevamente a todo: al pop vía Borges; a las chispas de la filología y el comparatismo americano de Pedro Henríquez Ureña, Alfonso Reyes y Ricardo Rojas (esos tres negritos que comprendieron la potencia de las formas y de la vida); al camp y a la voz del cielo que resuena en Manuel Puig (que rescribe el siglo xx y, por eso, es uno de los escritores más sofisticados de todos los tiempos); a la filología como manipulación genética a través de Eduardo Kac; a la relación autóctona entre naturaleza y arte de la poesía en García Lorca, Rilke y Juanele; a lo queer de Lewis Carrol y a lo infinito de Cesar Aira; al snobismo en Kojève y Barthes; a Youtube, el neolítico superior; a la teología (negativa, crítica) de Alejandra Pizarnick, de Jean Genet y de León Ferrari; a Giorgio Agamben, que a través de Pasolini y Lorca aparece como poeta; a los juicios de Flaubert y Baudelaire; al nombre "profesor» vía Enrique Pezzoni y al nombre «escritor» vía Quique Fogwill; a las sutilezas de su maestra, Anita Barrenechea; a figuras ineludibles, David Viñas y Beatriz Sarlo; al cine en la era de la reproducción digital (Guy Debord, Jean Luc Godard), al cine después de mañana (Lars Von Trier, M. Night Shyamalan, Albertina Carri), a un pensamiento sobre los nombres en Rafael Spregelburd; a una ética sobre la materialidad textual en el teatro de Alejandro Casona (pues se opera «sobre carne viva» hay que ser «fiel a tu Dick»); La primavera, ambigua, de Botticceli. Y sigue: Lucrecio, el Hombre de Cro-Magnon, los museos y las bienales, Herzog, La celestina, Copi, Rayuela, Sontang, Martianus Capella, Bellatin, Obama, Nietzsche, los zombies, el facismo: la lista agobia.

Veo el listado que delata la falta de mejores ideas de escritura y noto lo melancólico que hay en volver nuevamente a todo. En efecto, como hay vida todavía, 
también hay partes de nosotros que se vuelven «humo negro»: puertas (en-tornadas) que se cierran. Pero como no podría ser de otro modo, la alegre melancolía de Suturas, un tanto queer, no está bajo el signo de Saturno sino sobre el regazo de Dionisos: ¡dios de mil nombres! (el coro es de Ureña).

Otra vez Daniel Link nos ha llenado de joyitas iridiscentes que ha sacado del barro que a veces con horror llamamos presente, a veces sentido común, y a veces, incluso, polémica. Sin ánimos de polemizar pero sí de discutir y de debatir, estamos frente a un libro (la sistematización tartamuda y retardada del pensamiento de uno de los teóricos fundamentales de América Latina) que replantea una situación concreta de los lenguajes, de la literatura y de las otras artes en relación con lo viviente que, repito, hoy por hoy se encuentra en un estado crítico. No hay allí ningún deseo de novedad o de transformación alguna: acá, independientemente de cada deseo, estamos viviendo todavía. Miope sería no entender esta situación. Y peor aún, diría, no sentir este llamado: «espero que todo esto conduzca a una ética y funde una comunidad (la de aquellos que no tienen ni tendrán comunidad)»(659).

Notas

${ }^{1}$ Tampoco caigamos en el error de caracterizar las hipótesis de Ludmer como novedosas o, peor, inesperadas. Ludmer hacía varios años que venía dictando esas clases. $\mathrm{Al}$ respecto, Analía Gerbaudo (20II) ha señalado que el concepto «modos de leer» es armado a partir de «modos de ver» de John Berger (1972). Y que, por otro lado, ya en el seminario de 1985 se lee una definición concreta: «en la sociedad se enfrentan modos de leer» que también son «formas de acción», así las cosas, los «modos de escribir» serían una manera concreta de intervenir (o agitar), desde la Teoría Literaria por ejemplo, en esa «guerra» (Gerbaudo 20I5).

2 Los días 22 y 23 de agosto se realizó en Rosario el «Coloquio Internacional Ficciones en transición. Representaciones liminales en la literatura y la cultura visual latinoamericana contemporáneas». La actividad se enmarcó en un proyecto de investigación que Sandra Contreras dirige junto con Alejandra Laera, Álvaro Fernández Bravo y que integran Luz Horne, Cristian Molina, Mariana Catalin, Marcos Zangrandi, Mariela Herrero. Además, en el coloquio disertaron invitados como Florencia Garramuño, Paola Cortés-Roca, Félix Bruzzone, Irina Garbatzky, Alberto Giordano, Tamara
Kamenszain, Ana Paula Kiffer, Lucía de Leone, Julio Ramos, Luz Rodríguez Carranza, Karl Eric Schollhammer y Viviana Usubiaga.

En ese contexto (coloquio, proyecto, integrantes, invitados y el público que esos nombres y problemas convoca) resulta insoslayable que las primeras palabras, «Preliminares...» las tituló Contreras, sean estas: «La siguiente ya es seguramente, más que una hipótesis, una evidencia: la idea de que, en el contexto de las transformaciones del imaginario artístico de las últimas décadas y, desde luego, del estatuto mismo de lo real en el mundo de simulación y la mediación de las imágenes, la ficción atraviesa, por lo menos desde fines del siglo Xx, un proceso de mutación y re-significación». Y como el tema parece ineludible, en relación con la Supervivencia de las luciérnagas de Didi-Huberman y su doble desaparición (1975, 1983), agrega Contreras: «Es una vía por demás interesante, creo, para situar(nos en) nuestras lecturas del presente: pensar, por ejemplo, la posautonomía como un estado de la lectura —-Ludmer diría: modos de leer- antes que como una serie de rasgos de la literatura del presente; hablar de lecturas, antes que de literaturas, posautónomas». 
${ }^{3}$ La inseparabilidad entre vida y escritura, es algo que ha tenido una clara formulación en, valga la repetición, Borges. En «Del culto a los libros» se lee: «El mundo, según Mellarmé, existe para un libro: según Bloy, somos versículos o palabras o letras de un libro mágico, y ese libro incesante es la única cosa que hay en el mundo: es, mejor dicho, el mundo» (716). Actualmente, y según otra lógica, Mario Bellatin ha insistido de diversos modos en esta inseparabilidad: por ejemplo, al sostener cien mil veces que «la escritura es una sola».

\section{Bibliografía}

Antelo, Raúl (2008). Crítica acéfala. Buenos Aires: Grumo.

Barthes, Roland (1977). Fragmentos de un discurso amoroso. Buenos Aires: Siglo XXI, 2014.

Borges, Jorge Luis (1974). Obras Completas 1923-1972. Buenos Aires: Emecé.

Contreras, Sandra (2010). «En torno a las lecturas del presente», en Alberto Giordano, compilador. Los límites de la literatura. Rosario: Universidad Nacional de Rosario, I35-I53. (2014). «Preliminares del Coloquio». Coloquio Internacional Ficciones en transición. Representaciones liminales en la literatura y la cultura visual latinoamericana contemporáneas. Rosario: Universidad Nacional de Rosario. Mimeo.

Dalmaroni, Miguel (2010). «La literatura y sus restos (teoría, crítica, filosofía). A propósito de un libro de Ludmer (y de otros tres)». Bazar Americano 28 [en línea]. Consultado el I9 de octubre de 2015 en http://www.bazaramericano.com/columnas.php? $\operatorname{cod}=19 \& \mathrm{pdf}=\mathrm{si}$

Foucault, Michel (1982). «Pierre Boulez, l'écran traversé». Dits et écrits IV I980-I988. París: Gallimard, 1994, 219-222.

(1984). «Qué es la Ilustración?». Estética, ética y hermenéutica: Obras esenciales (vol. III). Barcelona: Paidós, 1999, 335-352.

Gerbaudo, Analía (20II). «Al margen de las garantías disciplinares, Josefina Ludmer». Katatay. Revista crítica de literatura latinoamericana 9, 83-93.

---. (2015). «Algo más sobre un mítico seminario (usina teórica de la Universidad argentina de la posdictadura)». $452^{\circ}{ }^{\circ}$ : revista de teoría de la literatura y literatura comparada I2, I32-I53.

LinK, DANiel (2003). Cómo se lee: y otras intervenciones críticas. Buenos Aires: Norma. (2005). Clases: literatura y disidencia. Buenos Aires: Norma. (2007, 26 de enero). «Entrevista a Daniel Link» [en línea], por Gabriela Manuli. Perfil. Consultado el 24 de octubre de 2015 en http://www.perfil.com/cultura/En-nuestraliteratura-la-vanguardia-ya-no-interesa-20070126-0034.html (2009). Fantasmas: capitalismo y esquizofrenia. Buenos Aires: Eterna Cadencia. (20ı0, II de julio). «Entrevista a Daniel Link» [en línea], por Carmen Perilli. La gaceta. Suplemento "La gaceta literaria». Consultado el 24 de octubre de 2015 en http://www.lagaceta.com.ar/nota/388077/la-gaceta-literaria/literatura-no-puede-pensarseseparadamente-tensiones-tiempo.html (2015). Suturas: imágenes, escritura, vida. Buenos Aires: Eterna Cadencia.

Ludmer, Josefina (2006). "Literaturas postautónoma» [en línea]. Linkillo (cosas mías). Consultado el 16 de octubre de 2015 en http://linkillo.blogspot.com.ar/2006/ı2/dicenque_I8.html

(20I0). Aqui América Latina: una especulación. Buenos Aires: Eterna Cadencia. 